\title{
Visualizing the Microdistribution of Zinc Borate in Oriented Strand Board Using X-Ray Microcomputed Tomography and SEM-EDX
}

\author{
Philip D. Evans, ${ }^{1,2}$ Vinicius Lube, ${ }^{1}$ Holger Averdunk, ${ }^{2}$ Ajay Limaye, 3 \\ Michael Turner, ${ }^{2}$ Andrew Kingston, ${ }^{2}$ and Timothy J. Senden ${ }^{2}$ \\ ${ }^{1}$ Centre for Advanced Wood Processing, University of British Columbia, Vancouver, BC, Canada V6T $1 Z 4$ \\ ${ }^{2}$ Department of Applied Mathematics, The Australian National University, Canberra, ACT 0200, Australia \\ ${ }^{3}$ Visualization Laboratory, Super-Computer Facility, The Australian National University, Canberra, ACT 0200, Australia \\ Correspondence should be addressed to Philip D. Evans; phil.evans@ubc.ca
}

Received 30 September 2014; Revised 27 January 2015; Accepted 12 February 2015

Academic Editor: Masamichi Kawai

Copyright (C) 2015 Philip D. Evans et al. This is an open access article distributed under the Creative Commons Attribution License, which permits unrestricted use, distribution, and reproduction in any medium, provided the original work is properly cited.

Oriented strand board (OSB) is an important wood composite used in situations where fungal decay and termite attack can occur. To counter these threats, powdered zinc borate biocide is commonly added to OSB. The effectiveness of biocides depends on their even distribution within composites and resistance to leaching, but little is known about the distribution of zinc borate in OSB. Zinc is denser than wood and it should be possible to map its distribution in OSB using X-ray micro-CT. We test this hypothesis and chemically register zinc in OSB using SEM-EDX. Zinc borate particles aggregated at the wood-adhesive interface in OSB, creating interrupted lines of zinc oriented in the $x-y$ plane. Zinc borate particles were also found in the lumens of wood cells. Zinc was distributed throughout OSB, although slightly less was present in the core of the composite than in surface layers. A network of zinc remained in OSB after leaching in water. The resistance of zinc to leaching may be due to its incorporation in glue-lines within $\mathrm{OSB}$, in addition to its low water-solubility. We conclude that X-ray micro-CT is a powerful tool for studying the distribution of zinc in OSB and other wood composites containing zinc borate.

\section{Introduction}

Oriented strand board (OSB) is a composite made by compressing and bonding together wood flakes with a thermosetting adhesive. OSB is the most common load-bearing wood composite panel used in North America, and current global production is approximately 20 million cubic metres per annum [1]. OSB is used for sheathing of buildings (walls, floors, and roofs), webs in structural I-beams, furniture frames, and industrial packaging (pallet tops, export crates, and boxes). In some of these end-uses OSB can be exposed to water for short periods of time. Hence, OSB contains wax to increase its resistance to moisture, and a biocide is often added to enhance its resistance to fungal and insect attack [2]. The most common biocide added to OSB is zinc borate $[3,4]$. Zinc borate is also used to protect other bio-based composites from fungal and insect attack, for example, waferboard, oriented structural straw-board, particleboard, medium density fibreboard, laminated strand lumber, bamboo scrimber, and wood plastic composites [4-6]. Zinc borate is added to OSB as a fine dry powder (1 to $2 \% \mathrm{w} / \mathrm{w}$ ) when wood, adhesive, and wax are blended together during the manufacture of OSB [2]. The resulting composite is resistant to both fungal and termite attack, although higher loadings of zinc borate are required to prevent such attack when wood composites are subjected to severe leaching with water [7].

The effectiveness of biocides at preventing fungal and insect attack of wood composites depends on their even distribution within the composite [8]. For example, Gnatowski et al. in their patent on determining biocide concentration in a composite wood product wrote that "uniform biocide distribution across the product enables economical and proper product protection against insects and fungi" [8]. They go on to say that "non-uniform concentration or distribution 
may lead to partial damage of the product by fungi or insects" [8]. Despite such statements, few studies have examined the distribution of zinc borate in OSB. Larkin and coworkers used scanning electron microscopy (SEM) and energy-dispersive analysis of X-rays (EDX) and Fourier transform Raman microscopy to examine the distribution of zinc and boron in the wood composite waferboard [9]. Their EDX dot-maps of boron and zinc show localized deposits of zinc borate adjacent to areas that are free of boron or zinc (presumably wood flakes). Their SEM images show individual zinc borate particles on the surface of wood flakes adjacent to adhesive deposits and woody debris. In addition to the latter research, a study of the decay resistance of OSB treated with zinc or calcium borate observed calcium borate particles within the lumens of hardwood flakes in OSB exposed to fungal decay [10]. The lack of information on the distribution of zinc borate in OSB is surprising because the distribution of other biocides in wood and wood composites has received much attention using a variety of analytical techniques including SEM in combination with EDX [11], inductively coupled plasma atomic emission spectroscopy [7], X-ray fluorescence microscopy [12], and X-ray microcomputed tomography (CT) [13]. We used X-ray micro-CT to visualize the microstructure of melamine-urea formaldehyde (MUF) glue lines in the wood composite, particleboard [14]. Wood and MUF adhesive have similar densities, and to visualize the adhesive in the composite we increased its density by covalently bonding copper sulphate to the MUF [14]. Once this was done it was possible to visualize the distribution of the MUF glue lines in the composite [14]. Visualizing the distribution of zinc borate in OSB should be easier because the atomic mass of zinc is similar to that of copper, and it should contrast with wood, voids, and also the thermosetting adhesive in the composite. Hence, we hypothesize that Xray micro-CT will be able to visualize the microdistribution of zinc in zinc-borate-treated OSB. We test this hypothesis here and also examine how the distribution of zinc in OSB is influenced by leaching of the composite in water. Our results clearly demonstrate that zinc borate is distributed throughout the OSB as interrupted lines of particles concentrated at the wood adhesive interface and oriented in the $x-y$ plane and, less commonly, as individual particles located in the lumens of the wood fibres in OSB strands.

\section{Materials and Methods}

2.1. Composite Samples. OSB samples measuring $51 \times 51 \mathrm{~mm}$ (length $\times$ width) and $10.5 \mathrm{~mm}$ in thickness were cut from each of eight full-sized OSB panels produced during separate production runs at a commercial OSB mill in Western Canada. The OSB was web-stock used for I-joists destined for export to Australia where there is a significant termite hazard. Hence, zinc borate was added to the web-stock when it was manufactured to increase its insect resistance. The webstock was manufactured from a mix of two nondurable wood species (75\% lodgepole pine (Pinus contorta, Dougl.) and 25\% aspen (Populus tremuloides Michx.)) bonded together with two different adhesives: phenol formaldehyde (surface layers) and polymeric methylene diphenyl diisocyanate (pMDI, core of boards). The density of the OSB samples after they were conditioned for 1 month at $20 \pm 1^{\circ} \mathrm{C}$ and $65 \pm 5 \%$ relative humidity and had a moisture content of $9.9 \%$ (St. Dev. = 0.4 ) was $688.2 \mathrm{~kg} / \mathrm{m}^{3}$ (St. Dev. $\left.=10.2\right)$. The thickness of a set of conditioned samples was measured in four places using a digital micrometer and samples were immersed in water for $72 \mathrm{~h}$. The thicknesses of the samples were remeasured immediately after immersion in water and again after they were reconditioned for 18 days. Thickness measurements were used to calculate the orthogonal (thickness) swelling of samples. Another set of samples measuring $25.4 \times 25.4 \mathrm{~mm}$ (length $\times$ width) $\times 10.5 \mathrm{~mm}$ (thickness) was subjected to leaching in water using the American Wood Protection Association Standard AWPA E-11 [15].

2.2. Scanning Electron Microscopy and Energy-Dispersive XRay Spectroscopy. Small conditioned OSB specimens measuring 10 (length) $\times 5$ (width) $\times 10.5 \mathrm{~mm}$ (thickness) were cut using a hand-held razor saw from parent OSB samples, including specimens subjected to leaching in water. The specimens were clamped one at a time in a small vice and cut with a hand-held, single-edged, razor blade while being viewed under a stereomicroscope, a method similar to the one we have used to prepare planar surfaces of solid wood for scanning electron microscopy [16]. Specimens were stored over silica gel for two days, trimmed to a final size of 10 (length) $\times 5$ (height) $\times 5 \mathrm{~mm}$ (width) and mounted on aluminium stubs using clear nylon nail polish as an adhesive. Specimens were coated with a thin layer of gold or carbon and viewed using a Zeiss Ultra Plus field emission scanning electron microscope equipped with an INCA Energy 450 energy-dispersive X-ray spectroscopy (EDX) system. We used an accelerating voltage of $15 \mathrm{kV}$ and a working distance of 12 to $15.1 \mathrm{~mm}$. The contrast between zinc borate and wood was greatest when images were formed from backscattered electrons and therefore we employed an angular sensitive backscatter detector (AsB) in preference to the in-lens or below-lens secondary electron detectors. Selected backscattered electron images of the surface of OSB specimens containing zinc borate (unleached and leached) were saved as TIFF files. Energy-dispersive X-ray spectroscopy was used to determine the elemental composition of individual points in imaged areas (point analysis) [17].

2.3. X-Ray Microcomputed Tomography. Oriented strand board specimens measuring $30 \times 16 \times 10.5 \mathrm{~mm}$ (unleached) or $30.5 \times 15.4 \times 13.1 \mathrm{~mm}$ (leached) were imaged using the X-ray micro-CT system designed and built at the ANU. The system is a fine-focus variety that uses a circular scanning trajectory. It consists of an X-ray source (X-Tek RTF-UF225), a rotation stage $($ Newport RV120PP), and a large $(400 \times 400 \mathrm{~mm})$ flat panel X-ray detector (PerkinElmer XRD $1621 \mathrm{xN}$ ) that has a $2048 \times 2048$ pixel array. The system design is opticsfree and obtains magnification through simple geometry by utilising the expanding wavefield and adjusting the sourcespecimen and source-detector distances. The lower bound on tomographic resolution of such systems is the radiographic 
resolution which corresponds to the diameter of the X-ray source, $3-5 \mu \mathrm{m}$ in this case. The voxel size of reconstructed tomograms can of course be smaller than this; however, when imaging the OSB specimens a voxel size of approximately $10.5 \mu \mathrm{m}$ was used.

Each OSB specimen was placed on the rotation stage, located $95 \mathrm{~mm}$ from the source, with the detector position $1800 \mathrm{~mm}$ from the source, and probed separately with a polychromatic X-ray beam (Bremsstrahlung radiation). For these experiments, the accelerating voltage of the electron beam generating the Bremsstrahlung radiation was $60 \mathrm{kV}$ with a current of $140 \mu \mathrm{A}$. A series of X-ray transmission radiographs, collectively called the projection data, were acquired by the detector as the specimen was rotated through 360 degrees over a period of $20 \mathrm{hrs}$. In order to satisfy Nyquists sampling criterion, the number of radiographs required in a projection set is approximately pi $\cdot N / 2$ for an $N \times N \times N$ voxel reconstruction; 2880 radiographs were taken in our experiments. A 3D volume of the X-ray attenuation property of each specimen, known as a tomogram, was reconstructed from the projection data set using the Feldkamp-Davis-Kress (FDK) algorithm [18]. The X-ray attenuation property of a material is proportional to density at a given X-ray energy; therefore, a tomogram can be viewed as a density map. The FDK algorithm is an approximate inverse of the Radon transform and assumes X-ray attenuation to be linear with material thickness. However, X-ray attenuation is not linear with material thickness and is a function of X-ray energy. Monochromatic (single-energy) X-ray projection data can be linearised according to the Beer-Lambert law and is then suitable for reconstruction via the FDK algorithm. This is not strictly true for polychromatic projection data and a similar manipulation of the data (as for monochromatic data) can produce beam-hardening artifacts in the tomogram. The term beam-hardening refers to the preferential attenuation of lower energy X-rays leading to a higher-energy (or harder) $\mathrm{X}$-ray beam. The simplest method to reduce beam-hardening artifacts is to filter the $\mathrm{X}$-ray beam. This prehardens the beam, reducing the energy distribution. A $2 \mathrm{~mm}$ thick glass filter was used when imaging the OSB specimens. Post-acquisition software beam-hardening correction methods exist [19, 20]; however, they were not employed here since the tomograms produced were of sufficient quality to unambiguously segment the wood, void, and zinc phases as described below.

2.4. Visualization and Numerical Analysis of Zinc in Orientated Strand Board. The mango software (http://www. physics.anu.edu.au/appmaths/capabilities/mango.php) was used for image enhancement and segmentation of the three different phases in the tomographic data: Phase $1=$ void; Phase 2 = wood; Phase 3 = zinc. Image enhancement is usually carried out on X-ray CT data sets because the data contains noise. Here, an anisotropic diffusion filter, which removes noise and enhances edges in the image, was used [21, 22]. Segmentation, the process of converting the data set into its three phases, used the converging active contours (CAC) method [22]. CAC was applied to the data sets twice and was followed by a step that reduced noise further by removing isolated clusters smaller than 10 voxels from Phase 2 (wood).
Segmentation was able to identify the different phases in the tomograms and quantify the percentages of each phase in unleached and leached OSB specimens. Quantitative information on the distribution of zinc in the composite used chord length analysis [23], which gives the probability that a randomly chosen chord in phase $i$ has length $r$. A chord is defined as any line segment which lies entirely in phase $i$ with end points at the phase interface. In this study, chords were traced through the zinc phase in all three orthogonal directions $(x, y$, and $z)$ in the composite. Data sets were visualized in $2 \mathrm{D}$ and $3 \mathrm{D}$ using volume rendering in which a transfer function assigns each voxel a colour and transparency [24]. The colour of wood flakes in OSB is initially rendered in their native brown colour to facilitate understanding of images. Thereafter images are rendered in colours that maximize contrast between wood (blue) and adhesive (yellow). Volume rendering was performed using the software Drishti, which is an open source volume exploration and presentation tool for visualizing tomographic data and is available at http://sf.anu.edu.au/ Vizlab/drishti/. Processing of CT data used a Compaq AlphaServer supercomputer located at the Australian Partnership for Advanced Computing, Australia's national supercomputing facility. Visualization of tomographic data with Drishti used a desktop computer equipped with a powerful graphics card (NVIDIA GeForce GTX 590, Santa Clara, CA, USA).

\section{Results and Discussion}

High intensity regions that are white in scanning electron microscopy (SEM) images could be clearly seen at the surface of unleached and leached oriented strand board (OSB) specimens when they were examined using field emission scanning electron microscopy. These high intensity regions were concentrated at the interface between the strands of pine and aspen in the composite and were present in both unleached and leached specimens (arrowed in Figure 1). Both types of specimens contained cracks, but they were larger in specimens that had been leached (compare Figure 1(a) versus Figure 1(b)), in accord with previous studies that have shown that leaching and subsequent drying cause delamination of OSB [25]. The high intensity regions, hereafter called white deposits, contrasted strongly with underlying wood when OSB specimens were observed using backscattered electrons (Figure 1). These electrons provide a signal that is dependent upon atomic number, suggesting that the deposits contained a heavy element, possibly zinc.

Point analysis of multiple white deposits using energydispersive X-ray spectroscopy (EDX) confirmed that they contained zinc (Figure 2(a)). EDX did not detect boron in the deposits, as expected, because the carbon coating used to make SEM specimens conductive strongly absorbs Xrays emitted by boron; secondly, X-ray emission of light elements such as boron is low and furthermore there is a high probability of X-rays being absorbed by the specimen [26]. Nevertheless, zinc borate particles could be clearly seen at higher magnifications in voids or in lumens of some cells within wood strands (Figures 2(b) and 2(c), arrowed). 


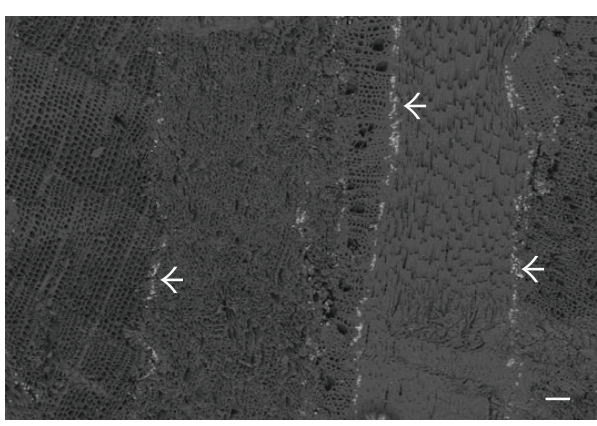

(a)

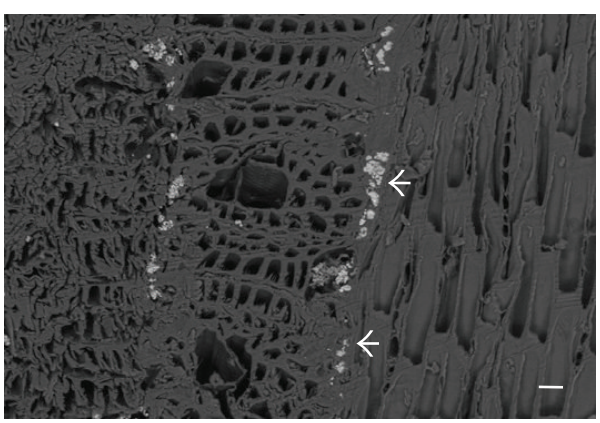

(c)

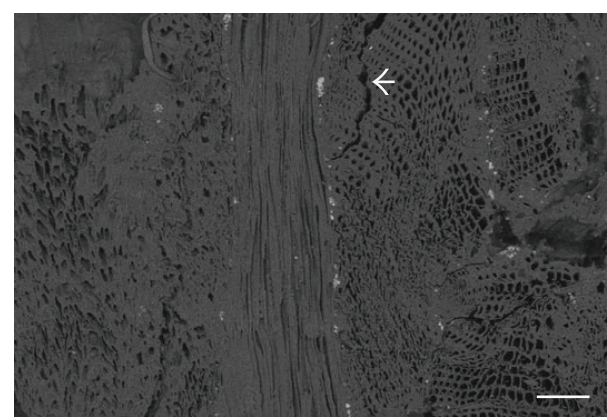

(b)

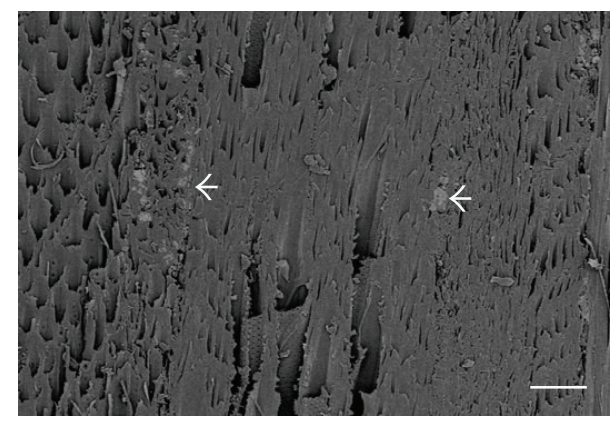

(d)

FIGURE 1: Backscattered scanning electron microscope images of sections of three different OSB specimens containing a zinc borate additive: (a) surface of an unleached specimen showing high intensity regions (white deposits) located between different wood flakes in the composite (arrowed); (b) leached specimen showing similar white deposits to those in (a). Note the microcheck in the specimen (arrowed top right); (c) enlarged area from (a) showing white deposits occurring at the interface between aspen (centre) and pine flakes (right); (d) surface of an unleached specimen showing white deposits occurring between two wood flakes in the composite (arrowed left) and the presence of an isolated white deposit (arrowed right). All scale bars are $100 \mu \mathrm{m}$ in length except for (c) which is $20 \mu \mathrm{m}$.

These particles were knobbly and irregular in shape and resembled the type 1 form of particles found in zinc borate powder and photographed by Gnatowski [27], rather than the rhomboids or irregular aggregates of spheres, platelets, and shards, which are also described in [27-29]. There was great variation in the size of zinc borate particles in OSB; for example, particles larger and smaller than $20 \mu \mathrm{m}$ and $1 \mu \mathrm{m}$, respectively, were common. In addition to these individual particles, zinc borate also occurred in a more homogeneous tightly packed form, filling the lumens of some wood cells (arrowed in Figure 2(d)).

Scanning electron microscopy is not very good at revealing the spatial distribution of elements in materials, as its field of view is small and it probes the surface rather than the bulk of a material, whereas X-ray micro-CT is commonly used to examine the spatial distribution of elements in rocks, polymers, and various biological materials including wood and wood composites $[13,14,23,24,30]$. Figure 3 shows rendered in-plane X-ray micro-CT images of unleached (Figure 3(a)) and leached (Figure 3(b)) OSB specimens. Denser material is rendered green. These dense "green" areas occur between the brown coloured wood elements in the OSB creating interrupted lines that are aligned in the $x-y$ plane. These lines resemble those observed in Figure 1, which were composed of white deposits containing zinc. The right-hand images in Figure 3 subtract wood and void from the coloured images and more clearly show the distribution of the denser material, hereafter referred to as zinc deposits.

The deposits of zinc in unleached OSB occur at the surface of flakes and in some cases trace the outline of flakes (arrowed in Figure 3(a)). We observed the same features in our previous study of the distribution of a melamineurea formaldehyde (MUF) adhesive in the wood composite particleboard [14], suggesting that some of the zinc borate and adhesive in the OSB are located together. Zinc borate is blown onto wood flakes at the same time as aqueous adhesive and wax during the manufacture of OSB. Powders adhere to wet tacky surfaces [31], and this probably also occurs when zinc borate powder is blended with wet resinated wood flakes, accounting for why zinc deposits are located at the wood adhesive interface in the OSB. The zinc appears to be fairly evenly distributed throughout the composite, although slightly less is present in the centre (core) of unleached OSB than in surface layers. In our previous study, which used $\mathrm{X}$-ray micro-CT to examine the morphology of MUF glue lines in particleboard, we observed that the continuity of the glue lines was more complete where there was better interparticle contact between flakes. We observed the same here, as can be seen in Figure 3(a) where deposits of zinc trace the outline of some flakes that are in good contact with each other. Such distribution was observed in numerous tomographic slices, but was more common in the surface 


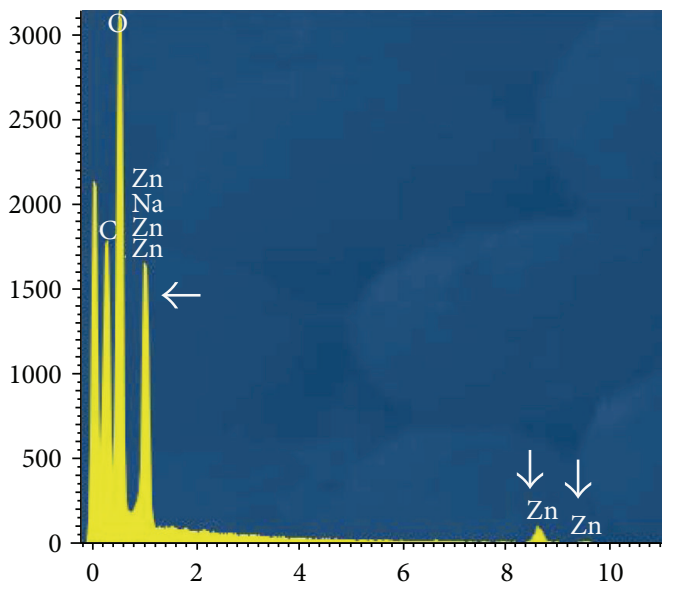

(a)

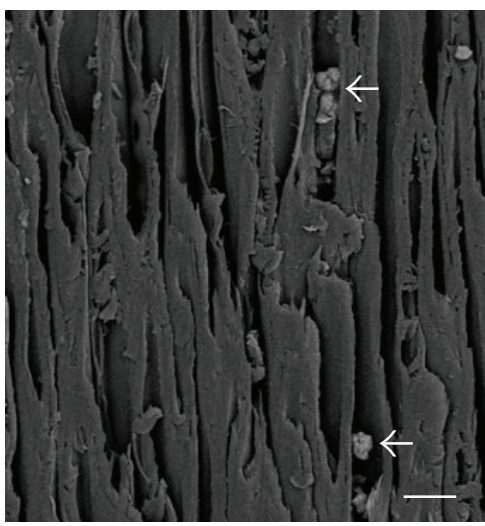

(c)

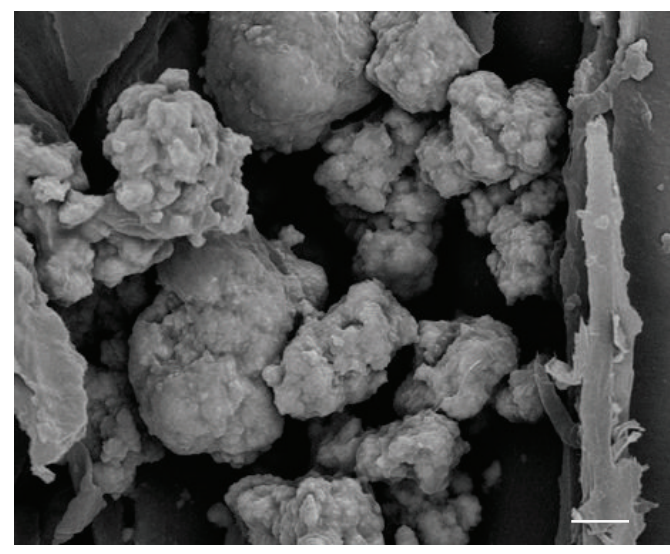

(b)

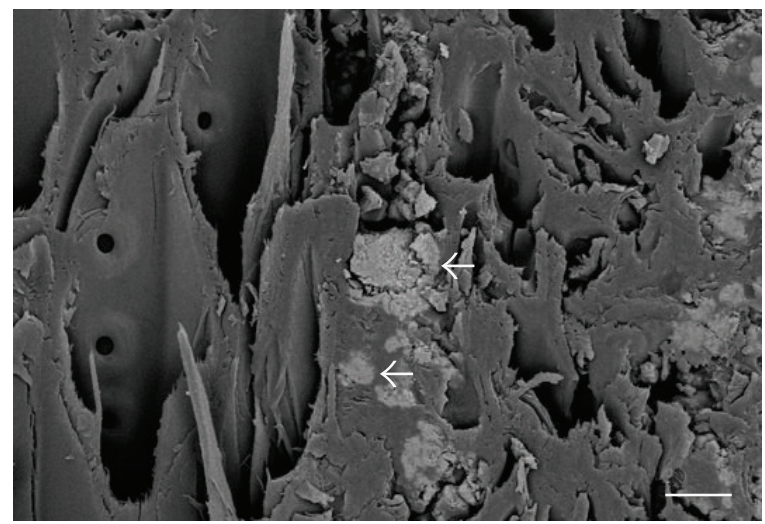

(d)

FIGURE 2: EDX spectrum and backscattered scanning electron microscope images of sections of OSB specimens containing a zinc borate additive: (a) EDX spectrum from point analysis of a white deposit in an OSB specimen. Note the prominent zinc peaks (arrowed) and the absence of boron peaks; (b) individual zinc borate particles in a void in an unleached OSB specimen; (c) individual zinc borate particles in lumens of cells (arrowed) in wood flakes in an unleached OSB specimen; (d) tightly packed zinc borate deposits in lumens of cells (arrowed) in wood flakes in an unleached OSB specimen. Scale bars are (b) $4 \mu \mathrm{m}$; (c) $20 \mu \mathrm{m}$; (d) $10 \mu \mathrm{m}$.

of the specimens presumably because greater densification of the surface when the OSB was pressed resulted in better interflake contact. Further evidence that zinc is associated with adhesive in the OSB is its concentration around small particles of wood or "fines" (Figure 4). Adhesive clumps to such small particles and hence reducing the "fines" in OSB is a common way of lowering the adhesive consumption and cost of manufacturing the composite [32].

The distribution of zinc in a leached OSB specimen is shown in Figure 3(b). Zinc is still mainly located at the interface between wood flakes, but the continuity of the deposits has been disrupted by delamination between flakes and also cracking of flakes. Such changes were associated with the pronounced orthogonal (thickness) swelling of the composite, which averaged $26.4 \%$ after OSB specimens were soaked in water for $72 \mathrm{~h}$ and reconditioned at $20 \pm$ $1{ }^{\circ} \mathrm{C}$ and $65 \pm 5 \%$ relative humidity for 18 days. Figure 3 also shows that zinc deposits were less distinct after the OSB samples were soaked in water. This may be caused by delamination and separation of glue lines containing zinc and the distribution of zinc over a greater area as a result of thickness swelling of specimens. The planar image of the water-soaked OSB specimen (Figure 3(b)) is not particularly good at showing spatial distribution of the zinc remaining in the specimen after leaching. Therefore we created 3D images showing the distribution of zinc in the leached and unleached specimens (Figure 5) and a 3D animation showing the distribution of zinc in the leached specimen (Figure 6). Figure 5 clearly shows the presence of a network of zinc in the OSB specimens before and after leaching, although the network is finer and more diffuse in the leached specimen, as images in Figure 3 suggested.

Figure 6 shows static sequential (left to right) images from an animation of part of a zinc borate treated OSB specimen subjected to leaching. The first part of this animation shows a rectangular block of OSB with light brown wood flakes and light blue "glue lines" containing zinc. Later the animation progressively reveals the distribution of zinc in the composite by subtracting a central "window" of wood from the block of OSB. The full animation can be found, played or downloaded 

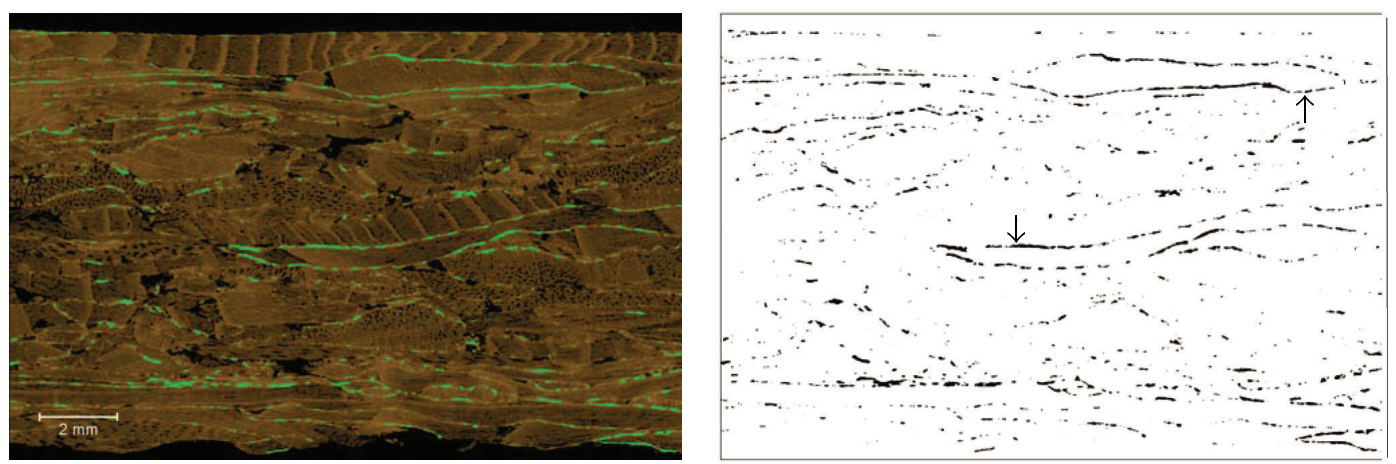

(a)
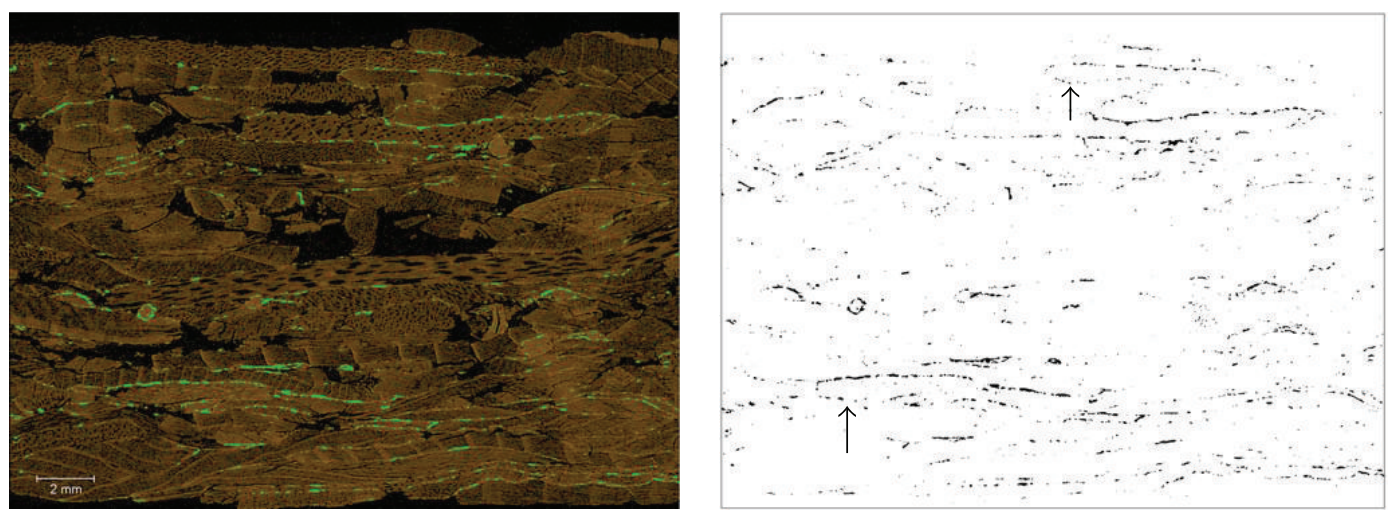

(b)

Figure 3: In-plane rendered X-ray micro-CT images of unleached (a) and leached (b) OSB specimens. Denser material (zinc) is rendered green; wood is rendered brown; and voids are black. Right-hand images more clearly show the denser material in black (subtracting wood and void from the images on the left).

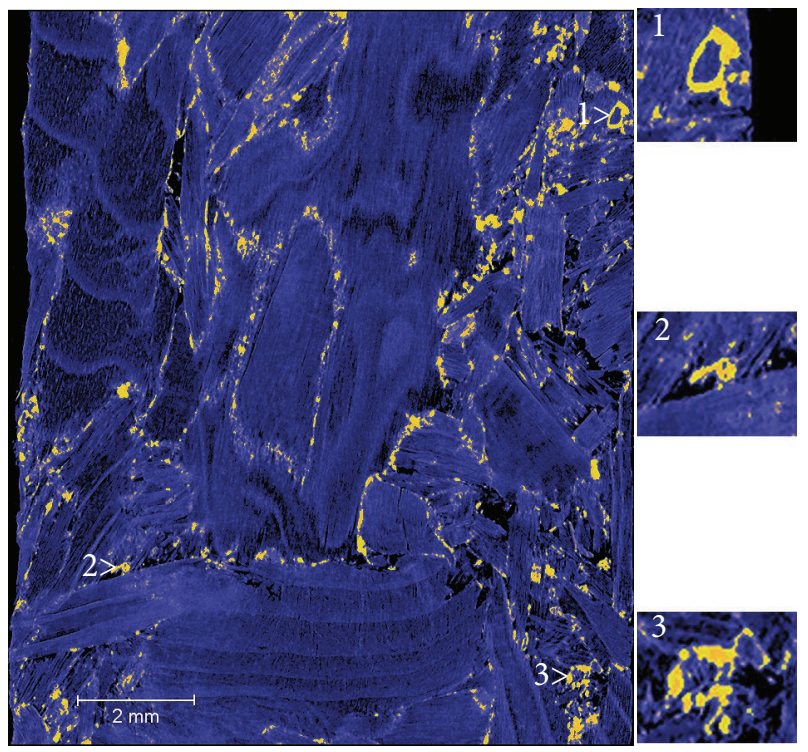

FIgURE 4: Orthogonal rendered X-ray micro-CT images of an unleached OSB specimen. The denser zinc is rendered yellow; wood is rendered blue; and voids are black. Note the clumping of zinc around small particles of wood (numbered on the left-hand image and enlarged in the right-hand images). at the following web-site https://www.onedrive.live.com/ redir? resid=7CDA96CBC892D009\%21107. This animation and the images in Figures 3 and 5 show that a discontinuous planar network of zinc exists within OSB even after a severe leaching regime. Such a network of zinc in the leached OSB specimens may explain, in part, why zinc borate is an effective biocide for OSB and other bio-based composites.

Chord length analysis was used to examine changes in the spatial distribution of zinc in the composite following leaching [23]. The frequency histograms of chord lengths in zinc in the $z$ and $x$ directions are shown in Figure 7. The frequency histograms for chord lengths in the $z$ direction show that leaching caused chord lengths to shift left to lower values. This shift indicates that deposits of zinc borate became thinner in the $z$ (thickness) direction as a result of leaching, possibly due to delamination of flakes and separation of glue lines that contained zinc borate. This suggestion accords with 2D and 3D images (above, Figures 3 and 5), which show that deposits of zinc were finer in the leached compared to unleached specimens. The frequency histograms for chord lengths in zinc in the $x$ and $y$ directions showed that leaching shifted chord lengths to the right. Such a shift to longer chord lengths, which was more pronounced in the $x$ direction (Figure 7) compared to the $y$ direction (not shown), may be associated with the straightening of flakes that occurs when 


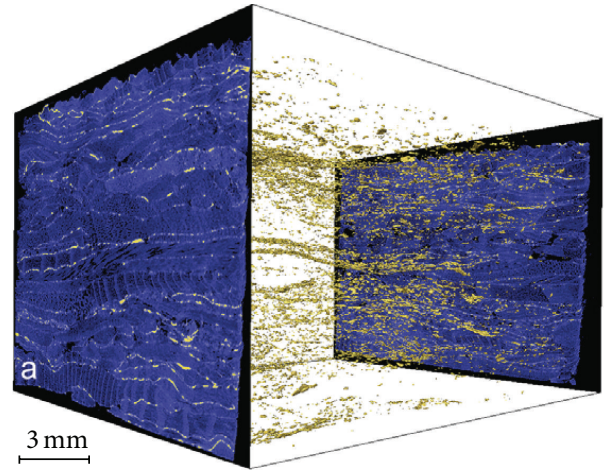

(a)

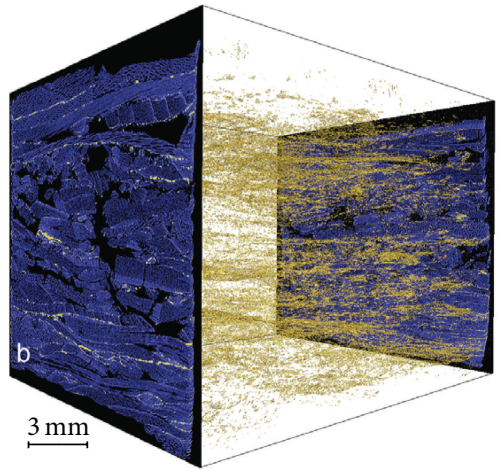

(b)

FIGURE 5: 3D rendered X-ray micro-CT images of unleached (a) and leached (b) OSB specimens. Note that denser material (zinc) is rendered yellow, wood is rendered blue; and voids are black. Note the presence of a network of zinc in the composite, which is finer and more diffuse in the leached specimen.
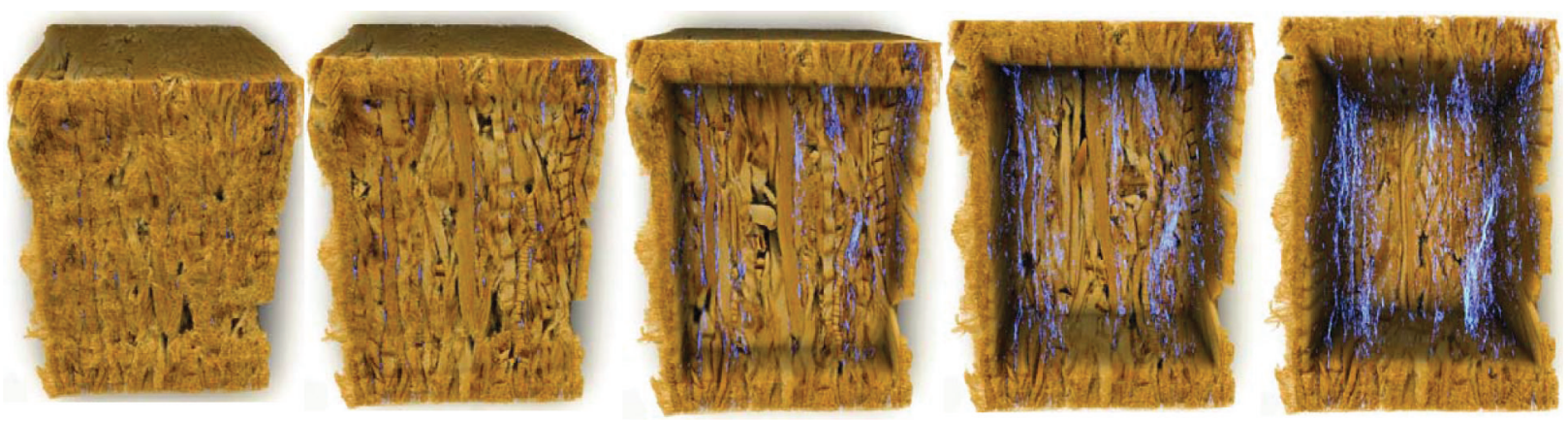

FIGURE 6: 3D rendered X-ray micro-CT images taken from an animation showing a block of OSB from a leached OSB specimen containing zinc borate. Wood is a tan colour, voids are black, and zinc is blue. Note the presence of a network of zinc in the central window of the composite after wood and voids have been removed.

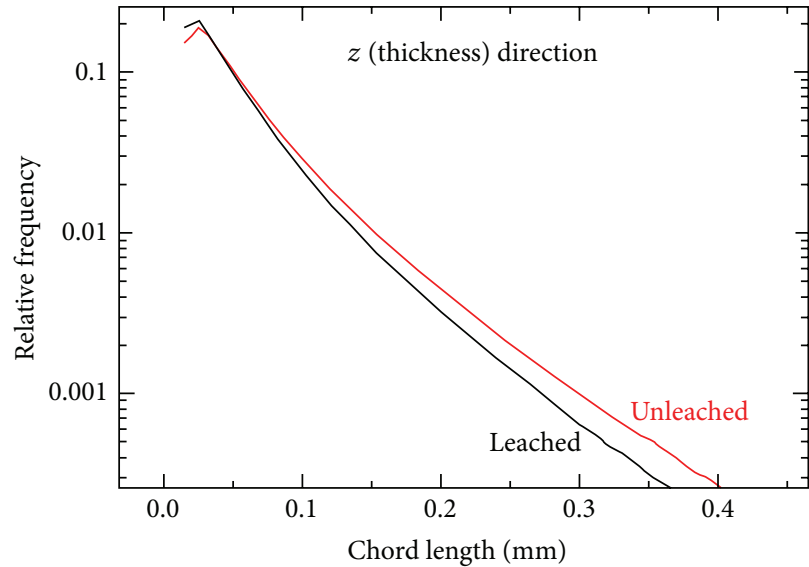

(a)

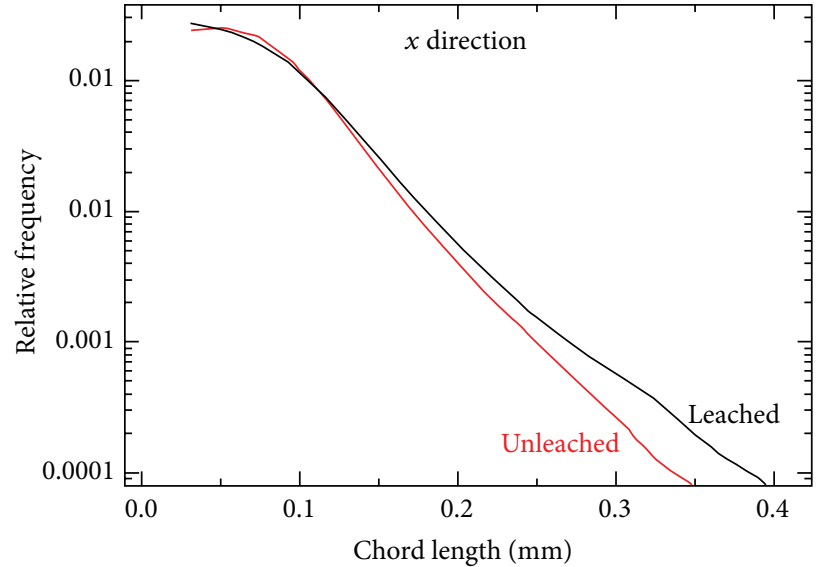

(b)

Figure 7: Chord length distributions for zinc in the $z$ and $x$ directions in unleached (red lines) and leached (black lines) oriented strand board specimens. 
strand-based wood composites undergo moisture induced thickness swelling [33, 34].

Numerical analysis of the different phases in unleached and leached specimens revealed that the void volume of the OSB increased following leaching from $29.6 \%$ to $48.8 \%$, in accord with the images above showing the presence of large voids in leached OSB (Figures 3 and 5). The unleached specimen contained $1.2 \%$ zinc compared to $0.8 \%$ in the leached specimen. The depletion of zinc in the composite accords with previous studies that have shown that severe laboratory leaching regimes deplete some of the zinc in OSB treated with zinc borate $[7,25]$. However, as the images above show, a network of zinc remains in the composite after leaching. The presence of residual zinc in OSB after leaching is certainly due to the low solubility of zinc borate as others have noted $[3,4]$, but our results suggest that it may also be due to its encapsulation in the polymer matrices of the thermosetting adhesives (PF and pMDI) used as the binders in the OSB. Further research is needed to confirm this suggestion which, if correct, may provide a way of controlling the release of zinc in the composite by altering the physical properties of the adhesives used in OSB.

\section{Conclusions}

We conclude that X-ray micro-CT can visualize zinc in oriented strand board containing the powdered biocide, zinc borate. Our findings should allow others to map the spatial distribution of zinc in the many other wood composites that are treated with zinc borate and also examine the effects of process variables and environmental factors on the distribution of zinc. We found that zinc was distributed throughout the OSB as interrupted lines of particles concentrated at the wood adhesive interface and oriented in the $x-y$ plane. Hence, we conclude that zinc is collocated with the adhesives used to bond wood flakes in OSB. Our SEM observations also show that some zinc borate particles are deposited the lumens of the wood fibres in OSB strands. Some zinc was lost when OSB was subjected to leaching in water, but a $3 \mathrm{D}$ network of zinc remained in the composite. The resistance of zinc to leaching may be due in part to its incorporation in the polymer matrices of the adhesives. Further research is needed to confirm this hypothesis, which, if correct, could lead to the development of ways of controlling the release of zinc within zinc borate treated OSB, possibly by modifying adhesive properties.

\section{Conflict of Interests}

The authors declare that they have no affiliations with or involvement with organizations that have financial interests in the subject matter or materials discussed in this paper.

\section{Acknowledgments}

The authors thank Dr. Frank Brink of the ANU's Centre for Advanced Microscopy for his help with scanning electron microscopy. Philip D. Evans thanks the Department of
Applied Mathematics at The Australian National University (ANU) for a Visiting Fellowship and Viance, Tolko, and FPInnovations for their support of his BC Leadership Chair at the University of British Columbia.

\section{References}

[1] P. D. Evans, M. Miesner, and D. Rogerson, "Machined tapers reduce the differential edge swelling of oriented strand board exposed to water," Composites Part B: Engineering, vol. 50, pp. $15-21,2013$.

[2] W. R. Smith and Q. Wu, "Durability improvement for structural wood composites through chemical treatments: current state of the art," Forest Products Journal, vol. 55, no. 2, pp. 8-17, 2005.

[3] P. E. Laks and M. J. Manning, "Preservation of wood composites with zinc borate," International Research Group on Wood Preservation Document no. IRG/WP 95- 30074, 1995.

[4] J. W. Kirkpatrick and H. M. Barnes, "Biocide treatments for wood composites-a review," International Research Group on Wood Protection Document no. IRG/WP 06- 40323, 2006.

[5] W.-S. Wei, F. Lu, D.-C. Qin, and X. An, "Effects of two kinds of boron-based fungicides on the properties of Bambusa emeiensis bamboo scrimber," Journal of Beijing Forestry University, vol. 34, no. 3, pp. 111-115, 2012.

[6] G. Han, M. Manning, W. Cheng, E. Pierre, and W. Wasylciw, "Performance of zinc borate-treated oriented structural straw board against mold fungi, decay fungi and termites-a preliminary trial," International Research Group on Wood Protection Document IRG/WP 11-40571, 2011.

[7] C. Tascioglu, K. Umemura, T. Yoshimura, and K. Tsunoda, "Biological performance of zinc borate-incorporated particleboard: effects of leaching on efficacy," Composites Part B: Engineering, vol. 57, pp. 31-34, 2014.

[8] M. J. Gnatowski, C. L. Mah, and G. P. Merrick, "Methods for determining organic biocide concentration in a composite wood product," US Patent 7,785,896 B2, 2010.

[9] G. M. Larkin, P. E. Laks, and M. P. Nelson, "The microdistribution of borate preservative in flake-based wood composites," in Proceedings of the Conference on Enhancing the Durability of Lumber and Engineered Wood Products, pp. 115-118, Forest Products Research Society, Kissimmee, Fla, USA, 2002.

[10] X. Xu, S. Lee, Y. Wu, and Q. Wu, "Borate-treated strand board from southern wood species: resistance against decay and mold fungi," BioResources, vol. 8, no. 1, pp. 104-114, 2013.

[11] H. Matsunaga, M. Kiguchi, and P. D. Evans, "Microdistribution of copper-carbonate and iron oxide nanoparticles in treated wood," Journal of Nanoparticle Research, vol. 11, no. 5, pp. 10871098, 2009.

[12] A. Zahora, "Further studies on the distribution of copper in treated wood using an XRF microscope technique," International Research Group on Wood Protection Document no. IRG/WP 10-40507, 2011.

[13] J. van den Bulcke, V. Biziks, B. Andersons et al., "Potential of $\mathrm{X}$-ray computed tomography for $3 \mathrm{D}$ anatomical analysis and microdensitometrical assessment in wood research with focus on wood modification," International Wood Products Journal, vol. 4, no. 3, pp. 183-190, 2013.

[14] P. D. Evans, O. Morrison, T. J. Senden et al., "Visualization and numerical analysis of adhesive distribution in particleboard using X-ray micro-computed tomography," International Journal of Adhesion and Adhesives, vol. 30, no. 8, pp. 754-762, 2010. 
[15] American Wood-Preservers'Association (AWPA), "Standard method of determining the leachability of wood preservatives," in Standard E11-97: AWPA Book of Standards, pp. 415-417, American Wood-Preservers'Association (AWPA), Selma, Ala, USA, 2004

[16] R. D. Heady, R. B. Cunningham, C. F. Donnelly, and P. D. Evans, "Morphology of warts in the tracheids of cypress pine (Callitris Vent.)," International Association of Wood Anatomists Journal, vol. 15, no. 3, pp. 265-281, 1994.

[17] J. C. Russ, Fundamentals of Energy Dispersive X-ray Analysis, Butterworths Monographs in Materials, Butterworths, 1984.

[18] I. A. Feldkamp, L. C. Davis, and J. W. Kress, "Practical conebeam algorithm," Journal of the Optical Society of America A: Optics and Image Science, and Vision, vol. 1, no. 6, pp. 612-619, 1984.

[19] G. van Gompel, K. van Slambrouck, M. Defrise et al., "Iterative correction of beam hardening artifacts in CT," Medical Physics, vol. 38, no. 1, pp. S36-S49, 2011.

[20] F. E. Boas and D. Fleischmann, "CT artifacts: causes and reduction techniques," Imaging in Medicine, vol. 4, no. 2, pp. 229-240, 2012.

[21] A. S. Frangakis and R. Hegerl, "Noise reduction in electron tomographic reconstructions using nonlinear anisotropic diffusion," Journal of Structural Biology, vol. 135, no. 3, pp. 239-250, 2001.

[22] A. P. Sheppard, R. M. Sok, and H. Averdunk, “Techniques for image enhancement and segmentation of tomographic images of porous materials," Physica A: Statistical Mechanics and its Applications, vol. 339, no. 1-2, pp. 145-151, 2004.

[23] C. H. Arns, F. Bauget, A. Limaye et al., "Pore-scale characterization of carbonates using X-ray microtomography," Society of Petroleum Engineers Journal, vol. 10, no. 4, pp. 475-484, 2005.

[24] M. A. Knackstedt, C. H. Arns, M. Saadatfar et al., "Elastic and transport properties of cellular solids derived from threedimensional tomographic images," Proceedings of the Royal Society A: Mathematical, Physical and Engineering Sciences, vol. 462, no. 2073, pp. 2833-2862, 2006.

[25] S.-Y. Lee and Q. Wu, "Leachability of zinc borate-modified oriented strandboard (OSB)," Mokchae Konghak, vol. 35, no. 5, pp. 46-57, 2007.

[26] H. Dijkstra, "Light element analysis," in Proceedings of 10th Regional Workshop on Electron Probe Microanalysis Today-Practical Aspects, A. M. Fioretti, Ed., pp. 35-43, Padua, Italy, 2012, http://fizweb.elte.hu/emas_2012/dijkstra_light_element_analysis001.pdf.

[27] G. M. Larkin, P. Merrick, M. J. Gnatowski, and P. E. Laks, "In-process protection of wood composites: an industry perspective," in Development of Commercial Wood Preservatives. Efficacy, Environmental, and Health Issues, T. P. Schultz, H. Militz, M. H. Freeman, B. Goodell, and D. D. Nicholas, Eds., vol. 982 of American Chemical Society Symposium Series, chapter 27, pp. 458-469, American Chemical Society, Washington, DC, USA, 2008.

[28] A. S. Kipcak, N. B. Acarali, E. M. Derun, N. Tugrul, and S. Piskin, "Effect of magnesium borates on the fire-retarding properties of zinc borates," Journal of Chemistry, vol. 2014, Article ID 512164, 12 pages, 2014.

[29] J. G. Gwon, S. Y. Lee, S. J. Chun, G. H. Doh, and J. H. Kim, "Physical and mechanical properties of wood-plastic composites hybridized with inorganic fillers," Journal of Composite Materials, vol. 46, no. 3, pp. 301-309, 2012.
[30] Y. Wang, L. Muszynski, and J. Simonsen, "Gold as an X-ray CT scanning contrast agent: effect on the mechanical properties of wood plastic composites," Holzforschung, vol. 61, no. 6, pp. 723730, 2007.

[31] Y. Suzuki and H. Ikura, "Slow-releasing medical preparation to be administered by adhering to a wet mucous surface," United States Patent No. US4292299, 1981.

[32] K. Groves, "Online detection and characterization of MPB wood furnish to optimize OSB mill processing efficiency," Forintek Canada Corporation Report, Forintek Canada, Vancouver, Canada, 2007, http://www.for.gov.bc.ca/hfd/library/ documents/bib106724Report.pdf.

[33] R. H. Lloyd, Investigations of thickness swelling in cement particleboards [B.Sc. thesis], University of Wales, Bangor, UK, 1984.

[34] M. A. Irle, "Technical terms: compaction ratio," Wood Based Panels International, vol. 21, no. 3, p. 52, 2001. 

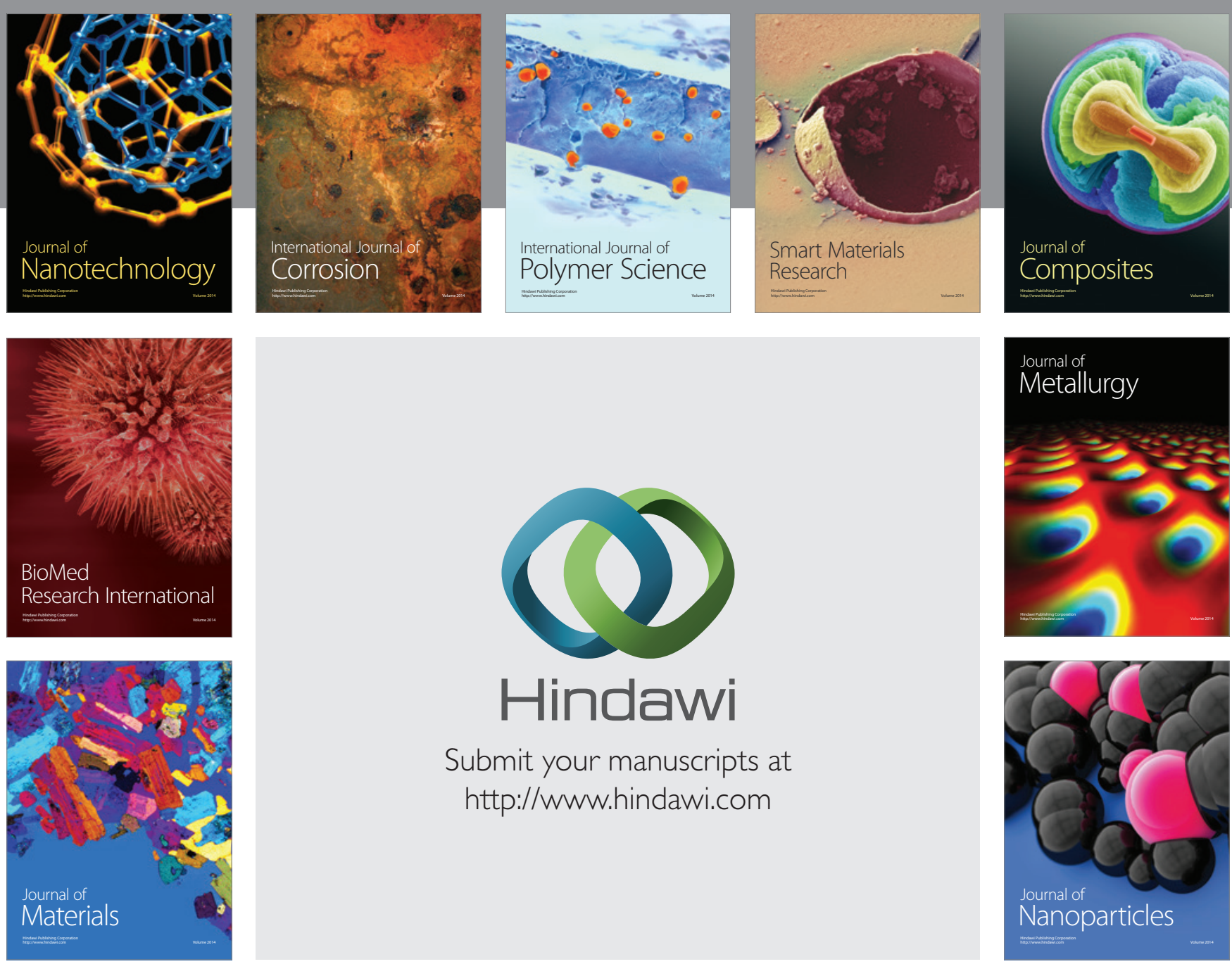

Submit your manuscripts at http://www.hindawi.com
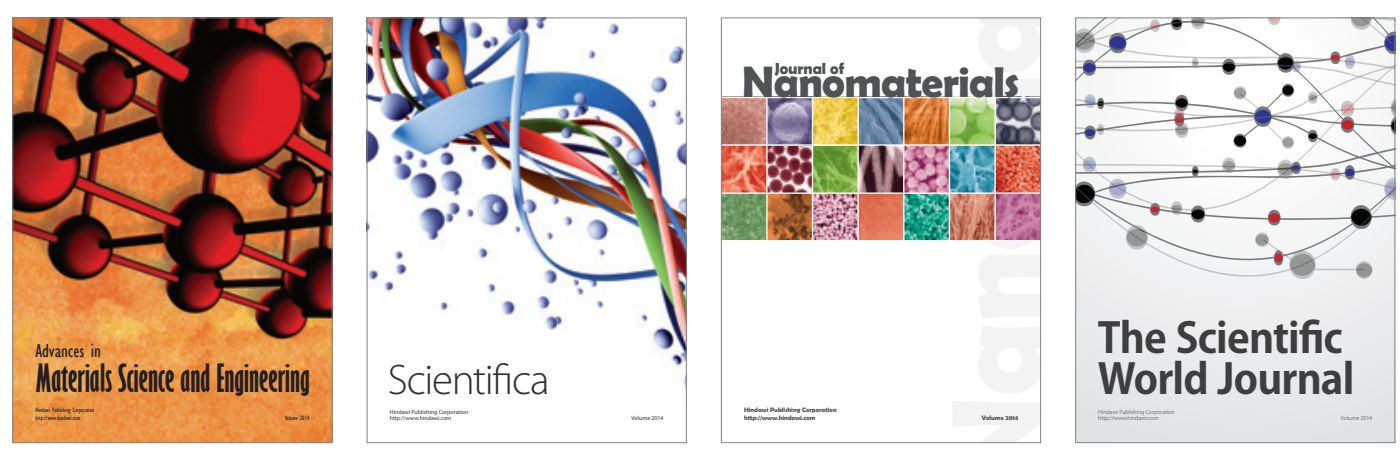

\section{The Scientific World Journal}
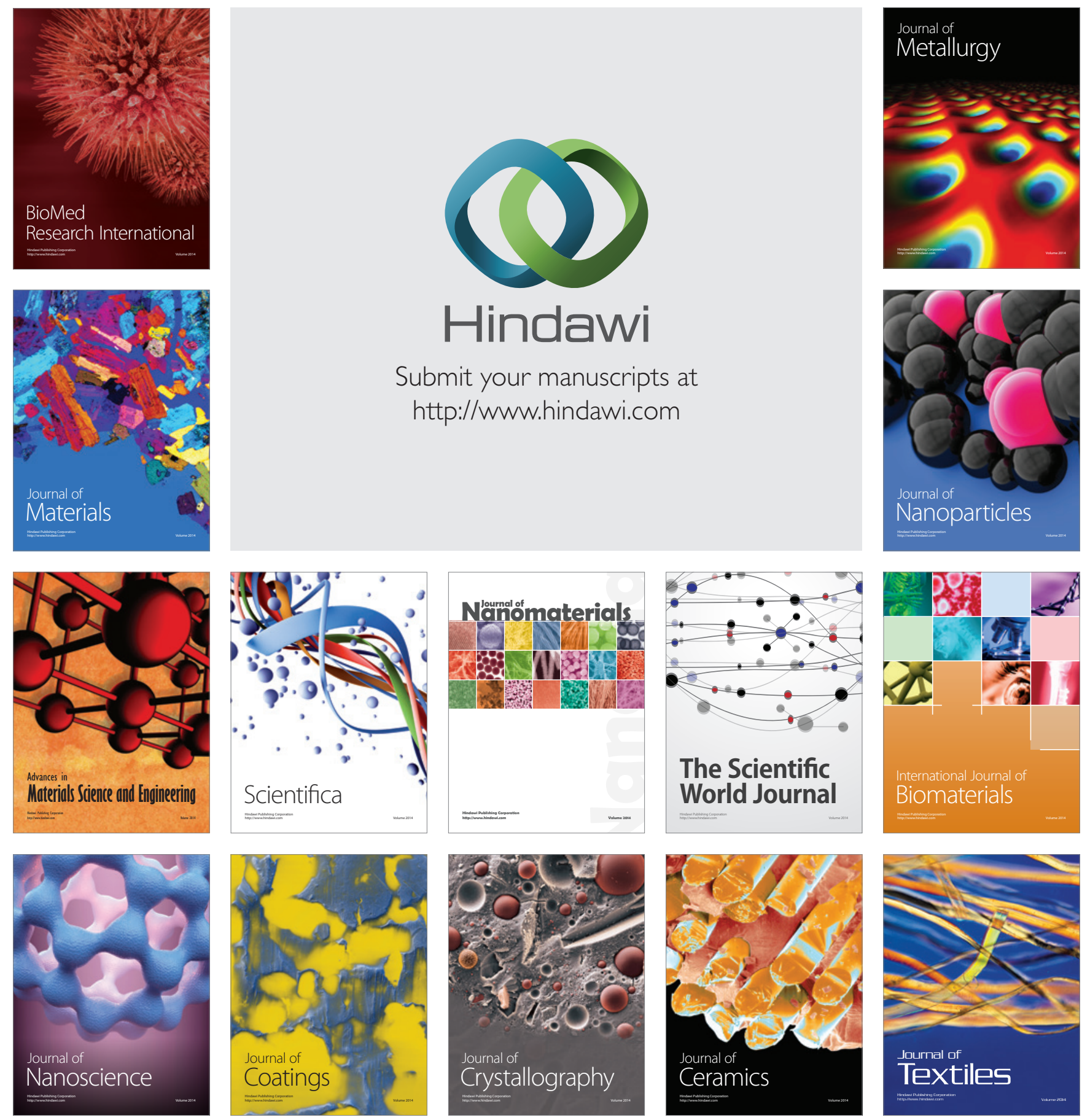